\title{
A Fractographic Study of Clinically Retrieved Zirconia-Ceramic and Metal-Ceramic Fixed Dental Prostheses
}

\author{
Zhen Pang, ${ }^{\text {a }}$ Asima Chughtai, ${ }^{a}$ Irena Sailer, ${ }^{b}$ Yu Zhang, ${ }^{\text {a* }}$
}

a Department of Biomaterials and Biomimetics, New York University College of Dentistry, New York, NY 10010, USA

b Division of Fixed Prosthodontics and Occlusion, School of Dental Medicine, University of Geneva, 19 rue Barthélemy-Menn, CH-1205 Geneva, Switzerland

*: corresponding author, yz21@nyu.edu

\author{
$4331^{\text {st }}$ Avenue, Room 810 \\ Department of Biomaterials and Biomimetics \\ New York University College of Dentistry \\ New York, NY 10010 \\ Tel.: (212) 998-9627 \\ Fax: (212) 995-4244 \\ Email: yz21@nyu.edu
}

For Dental Materials

January, 2015 


\section{ABSTRACT}

Objectives: A recent 3-year randomized controlled trial (RCT) of tooth supported three- to five-unit zirconia-ceramic and metal-ceramic posterior fixed dental prostheses (FDPs) revealed that veneer chipping and fracture in zirconia-ceramic systems occurred more frequently than those in metal-ceramic systems [1]. This study seeks to elucidate the underlying mechanisms responsible for the fracture phenomena observed in this RCT using a descriptive fractographic analysis.

Methods: Vinyl-polysiloxane impressions of 12 zirconia-ceramic and 6 metal-ceramic FDPs with veneer fractures were taken from the patients at the end of a mean observation of $40.3 \pm$ 2.8 months. Epoxy replicas were produced from these impressions [1]. All replicas were gold coated, and inspected under the optical microscope and scanning electron microscope (SEM) for descriptive fractography.

Results: Among the 12 zirconia-ceramic FDPs, 2 had small chippings, 9 had large chippings, and 1 exhibited delamination. Out of 6 metal-ceramic FDPs, 5 had small chippings and 1 had large chipping. Descriptive fractographic analysis based on SEM observations revealed that fracture initiated from the wear facet at the occlusal surface in all cases, irrespective of the type of restoration.

Significance: Zirconia-ceramic and metal-ceramic FDPs all fractured from microcracks that emanated from occlusal wear facets. The relatively low fracture toughness and high residual tensile stress in porcelain veneer of zirconia restorations may contribute to the higher chipping rate and larger chip size in zirconia-ceramic FDPs relative to their metal-ceramic counterparts. The low veneer/core interfacial fracture energy of porcelain-veneered zirconia 
may result in the occurrence of delamination in zirconia-ceramic FDPs.

Keywords: zirconia-ceramic FDPs; metal-ceramic FDPs; descriptive fractography; occlusal wear facet; chipping, delamination 


\section{Introduction}

Metal-ceramic and zirconia-ceramic systems are widely used for fixed dental prostheses (FDPs) today. Metal-ceramic FDPs were introduced to restorative dentistry several decades ago. This material system has good load-bearing capacity [2] and exhibits high survival rates. In addition, the reported rates for chipping of the veneering ceramic for metals were low. According to a 15 -year clinical study by Walton, only $3 \%$ porcelain veneer and $3 \%$ metal framework fracture were reported [3]. Yttria-tetragonal zirconia polycrystals $(\mathrm{Y}-\mathrm{TZP})$ is also widely used nowadays as an alternative material to metal for frameworks of posterior FDPs due to its high strength, good fracture toughness and excellent biocompatibility [4-6]. Y-TZP was found to have a flexural strength of $900-1200 \mathrm{MPa}$ [7] and fracture toughness of $4-6$ $\mathrm{MPa} \cdot \sqrt{ } \mathrm{m}[8-10]$. However, previous studies have reported high veneer chipping and fracture rate from $8 \%-25 \%$ in all major brands of zirconia-ceramic FDPs [11-20].

Even though many clinical studies have been conducted on zirconia-ceramic and metal-ceramic FDPs, very few studies presented a direct comparison of these two restorations. In order to directly assess the clinical performance of zirconia-ceramic and metal-ceramic FDPs, patients in a clinical trial should be randomly assigned to either zirconia-ceramic or metal-ceramic restorations. In addition, the numbers of these two types of restorations should be comparable. Both criteria have been met in a 3-year randomized controlled trial (RCT) for three- to five-unit zirconia-ceramic and metal-ceramic posterior FDPs conducted by Sailer et al. [1].

In Sailer's study, 38 metal-ceramic FDPs and 38 zirconia-ceramic were randomly placed in 59 patients who were generally and periodontally healthy with no bruxism. Out of these, 36 
zirconia-ceramic and 31 metal-ceramic FDPs were examined at mean observation period of $40.3 \pm 2.8$ months. The results showed that both zirconia and metal frameworks had excellent survivability, but the veneer chipping and fracture in zirconia-ceramic systems occurred more frequently than those in metal-ceramic systems. Among the 31 metal-ceramic FDPs, 19.4\% had veneer chipping. In contrast, the veneer chipping rate for 36 zirconia-ceramic FDPs was $33.4 \%$. Also, for the zirconia-ceramic system, the rate of the chipping down to the framework was $5.6 \%$, while the rate of restorations that needed to be replaced was $2.8 \%$. Sailer's study revealed that zirconia-ceramic FDPs underwent higher chipping rate and larger chipping size compared to their metal-ceramic counterparts after a three-year observation period [1].

A systematic fractographic analysis of the reasons for veneer fracture and for different clinical performances of zirconia-ceramic and metal-ceramic FDPs was not included in previous RCT studies. Descriptive fractography is an effective tool to identify the cause of failure and provide information about the loading conditions based on the fracture pattern recognition and analysis. Veneering ceramics of zirconia-ceramic and metal-ceramic FDPs are both brittle materials that have brittle fractures taking place with little or no plastic deformation. This nature helps brittle materials leave unequivocal patterns on fracture surfaces. The patterns are the direct consequence of crack perturbations during propagation [21]. Certain types of fractures leave telltale fracture patterns for the determination of fracture origin, direction of crack propagation and stress state. Some early studies successfully determined failure causes for clinically used dental restorations by descriptive fractography $[21,22]$. Then the systematic guide of this technique for clinically failed dental ceramics were established [23] based on the American Society for Testing and Materials (ASTM) standard 
practice [24]. In order to not disturb fracture surface after failure occurred, a replica technique for reproducing failed ceramic surfaces was introduced and its effectiveness for descriptive fractography was demonstrated by Scherrer et al. [25].

Accordingly, the purpose of this study was to determine the fracture origin, crack propagation path, and damage modes in veneer fractured zirconia-ceramic and metal-ceramic FDPs from Sailer's study using the replica technique and the principles of descriptive fractography.

\section{Materials and Methods}

\subsection{Specimen source}

Twelve zirconia-ceramic and 6 metal-ceramic FDPs with fracture from a previous randomized controlled trial $(\mathrm{RCT})$ conducted by Sailer et al. [1] were studied. The RCT included 59 patients ( 27 women and 32 men) that needed at least one FDP in the posterior region. All three- to five-unit posterior FDP sites were included and randomly assigned to either zirconia-ceramic or metal-ceramic restorations [1]. All patients had good general and periodontal health with no obvious signs of bruxism. Informed consent was obtained and the requirements of the Helsinki Declaration were fulfilled. The conventional preparation criteria for abutments of metal-ceramic and zirconia restorations were followed [1].

The zirconia and metal frameworks were fabricated out of presintered zirconia blanks (Cercon base 30 or 38, Dentsply, Pennsylvania, USA) and gold alloys (Degudent U, DeguDent, Hanau-Wolfgang, Germany), respectively. Two specially designed porcelain veneers were used for two different frameworks (veneering ceramic for zirconia: Cercon 
Ceram S, Ceramco, New Hampshire, USA; veneering ceramic for metal: Duceram Plus, Degudent, Hanau-Wolfgang, Germany). The porcelain firing protocols were provided by the manufacturer. In this case, both zirconia and metal FDPs were subjected to a so called fast cooling protocol, where the furnace was switched off after programed holding time at the elevated temperature. The furnace door was then opened and the FDP was left to cool. Details about the fabrication of FDPs have been published elsewhere [26].

After a mean period of $40.3 \pm 2.8$ months, fractured surfaces of 12 zirconia-ceramic and 6 metal-ceramic FDPs, which exhibited veneer chipping were cleaned with alcohol. After that, a low viscosity A-silicone impression material (President, Coltène Whaledent, Altstätten, Switzerland) was used to make impressions of FDPs surfaces [1]. Two impressions were made for each fracture surface. The first impression was to clean the surface. The second impression mold was used to cast the epoxy resin (EpoFix, Struers, Birmensdorf, Switzerland) replicas for fractographic studies. The epoxy was poured at least 1 hour after taking the impression mold.

\subsection{Specimen preparation}

All replicas were first cleaned using distilled water in an ultrasonic bath (Solid state/ultrasonic T-14B, L\&R, New jersey, USA). After cleaning, replicas were gold coated by the sputter coater (K650, Emitech, Massachusetts, USA).

\subsection{Specimen examination}

Specimens were inspected by stereomicroscope. Stereoptical microscope (SZX-ILLB100, Olympus, Pennsylvania, USA) equipped with a camera port (Retiga 32-0013B-118, Qimaging, Vancouver, Canada) and dual gooseneck fiber optic lights (Kramer, Fostec, Siheung-daero 
Siheung-si Gyeonggi-do, Korea) were used to examine fracture surfaces to determine different types of fracture (chipping, delamination or bulk fracture). Then, in order to elucidate the fracture origin and path of crack propagation, a scanning electron microscope (S-3500N, Hitachi, Tokyo, Japan) was used to inspect fracture surfaces.

\subsection{Descriptive fractographic analysis}

The fracture origins were located by fracture pattern analysis. We determined fracture origins by recognizing characteristic fracture patterns on fracture surface and tracing back to fracture initiation sites. The following three fracture patterns were used extensively in the descriptive fractographic analysis of replicas of fractured dental restorations including wake hackles, twist hackles and arrest lines.

Wake hackles are trails extending from an irregularity at the crack front in the direction of crackling [27]. Porcelain veneers for zirconia-ceramic and metal-ceramic restorations have a certain amount of pores introduced by the powder/water slurry technique for fabrication, which act as singularities [22]. When an advancing crack encounters an elastic singularity such as pores in porcelain, the crack front may split at the object and sweep past it on both sides. As the two fronts pass the obstacle they are often on slightly different planes and create a "tail" between them. The tail may fade away quickly or persist for long distances. The local crack runs the same way as the tail fades and the singularity side of wake hackle is the origin side of this fracture [27].

Twist hackles are formed when the stress field changes [27]. Veneering ceramics are glass reinforced with crystallites, which have coarse particles and agglomerates. Crack goes through coarse particles and agglomerates with local rotation in the axis of principal tension, 
so twist hackles are generated during the crack propagation. When the axis of principal stress is tilted, the crack is unable to rotate immediately, so it breaks into small, unconnected segments and leaves the "step", twist hackle, between different segments. Usually the crack propagation is in the direction of fine to coarse hackles and the side with fine hackles is the side of fracture origin [27].

Arrest lines are formed when a crack slightly changes the propagation direction [27]. During the crack propagation in dental restorations, the coarse grains make the crack hesitate or stop to redirect the path of crack propagation. When it hesitates or stops, the crack front profile becomes evident instantly in the form of arrest lines. The fracture origin would normally be on the concave side of an arrest line, and the convex direction is the direction of crack propagation [27].

These fracture patterns helped us not only to determine directions of crack propagation, but also to trace back to the fracture origins. From the different sites of fracture origins and the different stress fields specimens were involved in, we were able to elucidate sources and reasons for fracture.

\subsection{Definitions of fracture modes}

In order to facilitate ease of readership, we defined fractures that initiate from the occlusal surface but without exposing the framework as veneer chipping. Chipping area that involves less than one-fourth of the cusp was regarded as small chipping. Large chipping referred to the chipping area greater than one-fourth of the cusp. We designated fractures that extend to veneer/core interface as delamination. 


\section{Results}

The incidence of different types of fracture was summarized based on the stereomicroscope examination (Table 1). Then, the scanning electron microscope was used to discern the fracture origin and direction of crack propagation in fractured FDPs. In the interest of briefness, we selected only representative cases from each of the fracture modes. Detailed stereomicroscopic and SEM images of selective small and large chipping and delamination on the zirconia-ceramic and metal-ceramic FDPs are shown below.

\subsection{Zirconia-ceramic FDPs}

\section{Case 1: Small chipping in the left mandibular second molar (tooth \#37, retainer) of a}

\section{4-unit zirconia-ceramic FDP (Arrest lines, Twist hackles)}

In this left mandibular second molar of zirconia-ceramic FDP, there was a small chipping (white solid arrows) detected by stereomicroscope observation (Fig. 1a).

The direction of crack propagation was confirmed by twist hackles (white solid arrows) and arrest lines (black solid arrows) in Fig. 1b. The abundant arrest lines and twist hackles not only defined the direction of crack propagation (white dashed arrow in Fig. 1b) from the occlusal surface to the middle one-third of the mesio-lingual surface, but also pointed back to multiple fracture origins at the occlusal surface (black dashed circle) in Fig. 1c.

The occlusal view of fracture origins (black dashed circle) in Fig. 1c shows that these origins were located at the occlusal wear facets, indicating that the contact loading or impact on the occlusal surface was the cause of this fracture. Since no core material was exposed, it can be concluded that the fracture mode was chipping. 
Case 2: Large chipping in the left mandibular second molar (Tooth \#37, retainer) of a 3-unit zirconia-ceramic FDP (Arrest lines, Wake hackles)

In a left mandibular second molar of zirconia-ceramic FDP, a large chipping (white solid arrows) was detected by optical microscope (Fig. 2a).

The direction of crack propagation was recognizable from the characteristic features such as arrest lines and wake hackles. In Fig. 2b, indicators of the direction of crack propagation (black dashed arrows) are large arrest lines (white solid arrows). These indicators all suggest that the crack ran from the occlusal surface to the cervical one-third of disto-lingual surface. A noticeable area (black solid square in Fig. 2b) with high porosity was magnified in Fig. 2c. A series of wake hackles were left as trails emanating from pores when the crack front passed through these irregularities. This area contained crucial information on the direction of crack propagation (black dashed arrows in Fig. 2c). Therefore, the crack started from a region with excessive wear at the occlusal surface (black solid arrows) to the cervical one-third of disto-lingual surface (Fig. 2b). A higher magnification view of the fracture origin region (black solid arrows in Fig. 2b) is shown in Fig. 2 d, where the wear facets are clearly evident. Since no core material was exposed, this fracture was classified as a chipping.

Case 3: Delamination in the left mandibular first molar (tooth \#36, pontic) of a 4-unit zirconia-ceramic FDP (Twist hackles, Milling trace lines)

Fig. 3a shows an extensive fracture involving delamination (white solid arrows) in the left mandibular first molar of a zirconia-ceramic FDP.

In this case, the direction of crack propagation (black dashed arrows) was determined by twist hackles (white solid arrows) (Fig. 3b). The crack propagated from the region highlighted 
by a large black square to the cervical one-third of disto-lingual surface and distal surface (Fig. 3b). A higher magnification view of this highlighted region is shown in Fig. 3c, as can be seen the fracture origin (black dashed circle) is located at the region with substantial occlusal contact damage. During the crack propagation, the core material with distinct milling trace lines was exposed. A higher magnification image of the region highlighted by the small black square in $3 b$ is shown in Fig. $3 d$, where the characteristic markings from the CAD/CAM milling procedure can be revealed. These milling trace lines clearly demonstrated that this fracture mode was indeed delamination.

\subsection{Metal-ceramic FDPs}

Case 4: Small chipping in the left mandibular first molar (tooth \#36, pontic) of a

\section{3-unit metal-ceramic FDP (Arrest lines)}

A small chipping (white solid arrows) in the left mandibular first molar of a metal-ceramic FDP is shown in Fig. 4a. On this fractured surface, arrest lines, marked out by white solid arrows, were observed (Fig. 4b). These sharp arrest lines indicate that the crack ran from the occlusal surface towards the middle one-third of lingual surface (white dashed arrows). Since arrest lines are close to the occlusal surface, locations of fracture origins were determined to be at the occlusal surface. The occlusal view of fracture origins (white dashed circle) is shown in Fig. 4c. As can be seen, this fracture was initiated from the occlusal surface wear facet. Again, since no metal framework was exposed, it can be concluded that the fracture mode was chipping. 


\section{Discussion}

In the present study, after 3 years intra-oral service, 12 fractured zirconia-ceramic and 6 fractured metal-ceramic FDPs were examined by stereomicroscope and scanning electron microscope. Zirconia-ceramic FDPs had 2 small chippings, 9 large chippings and 1 delamination. Metal-ceramic FDPs had 5 small chippings and 1 large chipping with no delamination detected. Compared with metal-ceramic FDPs, zirconia-ceramic counterparts had higher chipping and delamination rate and larger chipping size. Among all the fractured specimens, regardless of the metal-ceramic or zirconia-ceramic FDPs, the fractures all originated from contact damage at the occlusal surface.

These findings are consistent with many previous clinical studies. For example, two 10-year longitudinal clinical trials reported an alarming $32 \%$ veneer chipping and $8.5 \%$ framework fracture rate in zirconia-ceramic FDPs [28], but only $10.6 \%$ veneer chipping rate in metal-ceramic FDPs [29], respectively. Also a systematic review of clinical performance of zirconia-ceramic and metal-ceramic FDPs revealed that the annual veneer chipping rate was $2.86 \%$ for zirconia-ceramic FDPs [30] and $0.58 \%$ for metal-ceramic FDPs (translated from $2.9 \%$ veneer chipping rate in a 5-year observation period) [31].

Our findings revealed that all fracture initiated from wear facets on the occlusal surface. However, zirconia-ceramic FDPs have a higher tendency of chipping and delamination due probably to lower fracture toughness of the veneering porcelain, greater residual stresses, and weaker interfacial fracture energy between the zirconia framework and porcelain veneer.

Wear surfaces often act as fracture initiation sites [23,32]. During mastication, dental restorations are subject to occlusal loading by the opposing teeth. Each chewing cycle 
involves contacting the mesial-distal cusp ridge, sliding down toward central fossa and then lifting off [33-35]. This sliding contact can create wear facets, where wear related microcracks can form $[36,37]$. These seemingly innocuous wear-induced microcracks could evolve into deleterious partial cone, inner cone, or median cracks [38-43] under the influence of mastication (cyclic fatigue loading) combined with the intrusion of saliva into surface fissures (hydraulic pumping) $[32,44]$. The rapid propagation of these occlusal-induced cracks can be responsible for premature veneer chipping and fracture $[45,46]$. In addition, once these cracks extend near the interface of the veneer porcelain and framework, continued masticatory loading can lead to delamination [47].

As alluded to in the preceding paragraph, fatigue fracture involves crack initiation and crack propagation. Two mechanical properties, strength and fracture toughness, are pertinent to crack evolution in ceramics. Even though the strength of the two tested porcelain veneering ceramics are similar ( 70 MPa) [48], the fracture toughness of the overlay porcelain for metal $(1.10 \mathrm{MPa} \cdot \sqrt{\mathrm{m}} \pm 0.13 \mathrm{MPa} \cdot \sqrt{\mathrm{m}})$ is significantly greater than that of the veneering porcelain for zirconia $(0.73 \mathrm{MPa} \cdot \sqrt{\mathrm{m}} \pm 0.02 \mathrm{MPa} \cdot \sqrt{\mathrm{m}})$ [49]. The lower fracture toughness leads to decreased resistance to crack propagation in porcelain fused to zirconia, suggesting that zirconia-ceramic FDPs have higher chipping rate and larger chipping size relative to metal-ceramic FDPs.

Fracture propagation is also affected by residual stresses. Residual stresses can develop in a porcelain veneer from coefficient of thermal expansion (CTE) mismatch between the veneer and framework, and from rapid cooling during the final cycle of porcelain firing. In metal-ceramic structures, CTE stresses may be beneficial, e.g. by placing the weak outer 
porcelain veneer into compression through the careful design of CTE mismatch. Typically the CTE of veneer is slightly smaller than that of metal coping, but the difference is no greater than $1 \mathrm{ppm} \mathrm{K}^{-1}$. Although the CTE mismatch in the current metal-ceramic and zirconia-ceramic systems are similar, which is only $0.5 \mathrm{ppm} \mathrm{K}^{-1}[47,50]$, the low thermal diffusivity property of zirconia framework could alter the distribution of thermal stresses in porcelain veneer $[49,51]$. Baldassarri et al. used the Vicker indentation method to estimate the magnitude and orientation of residual stresses in hand build-up zirconia-ceramic FDPs [52]. The results revealed a strong hoop compressive stress and a moderate tensile stress in the direction parallel and perpendicular to the veneer/core interface, respectively. The compressive stress suppresses crack propagation perpendicular to the veneer/core interface and contributes to the lower rate of delamination. The tensile stress leads to the tendency of crack propagation in the direction parallel to the porcelain/zirconia interface, which enlarges the chip size in zirconia-ceramic FDPs. So residual stresses in porcelain veneer due to the lower thermal diffusivity of zirconia framework may give rise to the higher chipping rate and larger chipping size in zirconia-ceramic FDPs than in metal-ceramic counterparts.

For the delamination case among all fractured zirconia-ceramic FDPs, the crack propagated down to the framework/veneer interface. This may be due to the low interfacial fracture energy of the zirconia framework and porcelain veneer [53]. When the crack front in the porcelain veneer reaches the veneer/core interface, it tends to choose a low fracture energy path, the interface, to propagate. Both clinical evidence and laboratory simulation [47] have demonstrated that interfacial cracks often graze along the weak interface for some distance, but eventually deflect back into the porcelain veneer rather than penetrate the stiffer 
and tougher zirconia core. Some previous studies have shown that the interfacial fracture energy ranges from $4.8 \mathrm{~N} / \mathrm{m}$ to $17.1 \mathrm{~N} / \mathrm{m}$ for a variety of commercial porcelain/zirconia systems with rapid or slow cooling rate [53-55]. However, the metal/porcelain interfacial fracture energy is as high as $72.7 \mathrm{~N} / \mathrm{m}$ for gold and $58.5 \mathrm{~N} / \mathrm{m}$ palladium [56,57]. So the delamination in zirconia-ceramic FDPs may be attributed to the low interfacial fracture energy in porcelain veneered zirconia restorations.

We acknowledge that the current descriptive fractographic analysis is based on a three-year RCT of zirconia-ceramic and metal-ceramic FDPs. Thus some phenomena, such as framework fracture and, perhaps, higher incidence of delamination, may appear over time, especially in zirconia-ceramic FDPs. The next step would be to do a descriptive fractographic analysis on the 5 to 10 years continuation of this RCT. This would help us assess whether the fracture modes observed in these dental restorations will change. It could also help us determine if the incidence of fracture will increase in both kinds of fixed dental prostheses.

\section{Conclusions}

(i) Zirconia-ceramic FDPs exhibited a higher rate of veneer chipping and delamination, as well as larger chipping size relative to metal-ceramic FDPs under the same intra-oral conditions.

(ii) All the fracture initiated from occlusal surface wear facets due to near-contact microcracking introduced by mastication.

(iii) Seemingly innocuous, wear-induced microcracks could rapidly propagate under the influence of mastication and intrusion of saliva, resulting in veneer chipping and fracture. 


\section{Acknowledgements}

Funding was provided by the United States National Institute of Dental and Craniofacial Research (Grant 2R01 DE017925) and the National Science Foundation (Grant CMMI-0758530). 


\section{REFERENCES}

1. Sailer I, Gottnerb J, Kanelb S, Hammerle $\mathrm{CH}$. Randomized controlled clinical trial of zirconia-ceramic and metal-ceramic posterior fixed dental prostheses: A 3-year follow-up. Int J Prosthodont 2009; 22:553-560.

2. Raigrodski AJ, Chiche GJ. All-ceramic fixed partial dentures, part i: In vitro studies. J Esthet Restor Dent 2002; 14:188-191.

3. Walton TR. An up to 15-year longitudinal study of 515 metal-ceramic fpds: Part 1. Outcome. Int J Prosthodont 2002; 15:439-445.

4. Sadan A, Blatz MB, Lang B. Clinical considerations for densely sintered alumina and zirconia restorations: Part 1. Int J Periodontics Restorative Dent 2005; 25:213-219.

5. Sadan A, Blatz MB, Lang B. Clinical considerations for densely sintered alumina and zirconia restorations: Part 2. Int J Periodontics Restorative Dent 2005; 25:343-349.

6. Manicone PF, Rossi lommetti P, Raffaelli L. An overview of zirconia ceramics: Basic properties and clinical applications. J Dent 2007; 35:819-826.

7. Piconi C, Maccauro G. Zirconia as a ceramic biomaterial. Biomaterials 1999; 20:1-25.

8. Srikanth R, Kosmac T, Bona AD, Yin L, Zhang Y. Effects of cementation surface modifications on fracture resistance of zirconia. Dental Materials, in press.

9. Lawn BR, Pajares A, Zhang Y, Deng Y, Polack MA, Lloyd IK, Rekow ED, Thompson VP. Materials design in the performance of all-ceramic crowns. Biomaterials 2004; 25:2885-2892.

10. Kosmac T, Oblak C, Jevnikar P, Funduk N, Marion L. The effect of surface grinding and sandblasting on flexural strength and reliability of y-tzp zirconia ceramic. Dent Mater $1999 ; 15: 426-433$.

11. Larsson C, Vult von Steyern P, Nilner K. A prospective study of implant-supported full-arch yttria-stabilized tetragonal zirconia polycrystal mandibular fixed dental prostheses: Three-year results. Int J Prosthodont 2010; 23:364-369.

12. Ortorp A, Kihl ML, Carlsson GE. A 3-year retrospective and clinical follow-up study of zirconia single crowns performed in a private practice. J Dent 2009; 37:731-736. 
13. Ohlmann B, Rammelsberg P, Schmitter M, Schwarz S, Gabbert O. All-ceramic inlay-retained fixed partial dentures: Preliminary results from a clinical study. J Dent $2008 ; 36: 692-696$.

14. Molin MK, Karlsson SL. Five-year clinical prospective evaluation of zirconia-based denzir 3-unit fpds. Int J Prosthodont 2008; 21:223-227.

15. Crisp RJ, Cowan AJ, Lamb J, Thompson O, Tulloch N, Burke FJ. A clinical evaluation of all-ceramic bridges placed in UK general dental practices: First-year results. Br Dent $\mathrm{J}$ $2008 ; 205: 477-482$.

16. Tinschert J, Schulze KA, Natt G, Latzke P, Heussen N, Spiekermann H. Clinical behavior of zirconia-based fixed partial dentures made of dc-zirkon: 3-year results. Int J Prosthodont 2007; 21:217-222.

17. Sailer I, Feher A, Filser F, Gauckler LJ, Luthy H, Hammerle CH. Five-year clinical results of zirconia frameworks for posterior fixed partial dentures. Int J Prosthodont 2007; 20:383-388.

18. Larsson C, Vult von Steyern P, Sunzel B, Nilner K. All-ceramic two- to five-unit implant-supported reconstructions. A randomized, prospective clinical trial. Swed Dent J $2006 ; 30: 45-53$.

19. Vult von Steyern P, Carlson P, Nilner K. All-ceramic fixed partial dentures designed according to the dc-zirkon technique. A 2-year clinical study. J Oral Rehabil 2005; 32:180-187.

20. Pospiech P, Rountree P, Nothdurft F. Clinical evaluation of zirconia-based all-ceramic posterior bridges: Two-year results. J Dent Res 2003; 82:

21. Quinn JB, Quinn GD, Kelly JR, Scherrer SS. Fractographic analyses of three ceramic whole crown restoration failures. Dent Mater 2005; 21:920-929.

22. Kelly JR, Giordano R, Pober R, Cima MJ. Fracture surface analysis of dental ceramics: Clinically failed restorations. Int J Prosthodont 1990; 3:430-440.

23. Scherrer SS, Quinn JB, Quinn GD, Kelly JR. Failure analysis of ceramic clinical cases using qualitative fractography. Int J Prosthodont 2006; 19:185-192. 
24. ASTM C 1322-96. Standard practice for fractography and characterization of fracture origins in advanced ceramics. Annual book of ASTM standards, vol. 15.01, West Conshohocken, PA: ASTM.

25. Scherrer SS, Quinn JB, Quinn GD, Wiskott H. Fractographic ceramic failure analysis using the replica technique. Dental materials 2007; 23:1397-1404.

26. Filser $F$, Kocher $P$, Weibel $F$, Lüthy $H$, Schärer $P$, Gauckler L. Reliability and strength of all-ceramic dental restorations fabricated by direct ceramic machining (DCM). Int $\mathrm{J}$ Comput Dent 2001; 4:89-106.

27. Quinn G. Fractography of ceramics and glasses. A nist recommended practice guide; special publication 960-16. National Institute of Standards and Technology, Washington, DC 2007.

28. Sax C, Hammerle $\mathrm{CH}$, Sailer I. 10-year clinical outcomes of fixed dental prostheses with zirconia frameworks. Int J Comput Dent 2011; 14:183-202.

29. Näpänkangas R, Salonen-Kemppi M, Raustia A. Longevity of fixed metal ceramic bridge prostheses: A clinical follow-up study. J Oral Rehabil 2002; 29:140-145.

30. Sailer I, Pjetursson BE, Zwahlen M, Hämmerle $\mathrm{CH}$. A systematic review of the survival and complication rates of all-ceramic and metal-ceramic reconstructions after an observation period of at least 3 years. Part ii: Fixed dental prostheses. Clin Oral Implants Res 2007; 18:86-96.

31. Pjetursson BE, Bragger U, Lang NP, Zwahlen M. Comparison of survival and complication rates of tooth-supported fixed dental prostheses (fdps) and implant-supported fdps and single crowns (scs). Clin Oral Implants Res 2007; 18 Suppl 3:97-113.

32. Zhang Y, Sailer I, Lawn BR. Fatigue of dental ceramics. J Dent 2013; 41:1135-1147.

33. Kim JW, Kim JH, Janal MN, Zhang Y. Damage maps of veneered zirconia under simulated mastication. J Dent Res 2008; 87:1127-1132.

34. Kim JH, Kim JW, Myoung SW, Pines M, Zhang Y. Damage maps for layered ceramics under simulated mastication. J Dent Res 2008; 87:671-675.

35. DeLong R, Douglas WH. Development of an artificial oral environment for the testing of dental restoratives: Bi-axial force and movement control. J Dent Res 1983; 62:32-36. 
36. Ren L, Zhang Y. Sliding contact fracture of dental ceramics: Principles and validation. Acta Biomater 2014; 10:3243-3253.

37. Peterson IM, Pajares A, Lawn BR, Thompson VP, Rekow ED. Mechanical characterization of dental ceramics by hertzian contacts. J Dent Res 1998; 77:589-602.

38. Zhang Y, Lawn BR. Competing damage modes in all-ceramic crowns: Fatigue and lifetime. Key Eng Mater 2005; 284:697-700.

39. Bhowmick S, Zhang Y, Lawn BR. Competing fracture modes in brittle materials subject to concentrated cyclic loading in liquid environments: Bilayer structures. J Mater Res 2005; 20:2792-2800.

40. Zhang Y, Bhowmick S, Lawn BR. Competing fracture modes in brittle materials subject to concentrated cyclic loading in liquid environments: Monoliths. J Mater Res 2005; 20:2021-2029.

41. Hermann I, Bhowmick S, Zhang Y, Lawn BR. Competing fracture modes in brittle materials subject to concentrated cyclic loading in liquid environments: Trilayer structures. J Mater Res 2006; 21:512-521.

42. Kim JW, Kim JH, Thompson VP, Zhang Y. Sliding contact fatigue damage in layered ceramic structures. J Dent Res 2007; 86:1046-1050.

43. Zhang Y, Kim JW, Kim JH, Lawn BR. Fatigue damage in ceramic coatings from cyclic contact loading with a tangential component. J Am Ceram Soc 2008; 91:198-202.

44. Zhang Y, Song JK, Lawn BR. Deep-penetrating conical cracks in brittle layers from hydraulic cyclic contact. J Biomed Mater Res B Appl Biomater 2005; 73:186-193.

45. Zhang $\mathrm{Y}$, Chai $\mathrm{H}$, Lee J-W, Lawn B. Chipping resistance of graded zirconia ceramics for dental crowns. J Dent Res 2012; 91:311-315.

46. Zhang $\mathrm{Y}$, Lee JJ, Srikanth R, Lawn BR. Edge chipping and flexural resistance of monolithic ceramics. Dent Mater 2013; 29:1201-1208.

47. Baldassarri M, Zhang Y, Thompson VP, Rekow ED, Stappert CF. Reliability and failure modes of implant-supported zirconium-oxide fixed dental prostheses related to veneering techniques. J Dent 2011; 39:489-498.

48. Materials Data Sheets, Dentsply 2004. 
49. Quinn JB, Quinn GD, Sundar V. Fracture toughness of veneering ceramics for fused to metal (pfm) and zirconia dental restorative materials. J Res Natl Inst Stand Technol $2010 ; 115: 343-352$.

50. Swain MV. Unstable cracking (chipping) of veneering porcelain on all-ceramic dental crowns and fixed partial dentures. Acta Biomater 2009; 5:1668-1677.

51. Zhang Y, Kim JW. Graded zirconia glass for resistance to veneer fracture. J Dent Res 2010; 89:1057-1062.

52. Baldassarri M, Stappert CF, Wolff MS, Thompson VP, Zhang Y. Residual stresses in porcelain-veneered zirconia prostheses. Dent Mater 2012; 28:873-879.

53. Chai $\mathrm{H}$, Lee JJ-W, Mieleszko AJ, Chu SJ, Zhang Y. On the interfacial fracture of porcelain/zirconia and graded zirconia dental structures. Acta biomaterialia 2014;

54. Le Thanh R. Adhesion of Veneering Porcelain to Zirconium Dioxide Ceramic as Determined by the Strain Energy Release Rate: The University of Sydney; 2009

55. Göstemeyer G, Jendras M, Dittmer MP, Bach F-W, Stiesch M, Kohorst P. Influence of cooling rate on zirconia/veneer interfacial adhesion. Acta biomaterialia 2010; $6: 4532-4538$

56. Suansuwan N, Swain MV. New approach for evaluating metal-porcelain interfacial bonding. Int J Prosthodont 1999; 12:547-552.

57. Tholey MJ, Waddell JN, Swain MV. Influence of the bonder on the adhesion of porcelain to machined titanium as determined by the strain energy release rate. Dent Mater 2007; 23:822-828. 
Figure Captions:

Fig. 1. A small chipping in the left mandibular second molar (tooth \#37, retainer) of a 4-unit zirconia-ceramic FDP. (a) An overview of veneer fracture. Fracture margins are highlighted by white solid arrows. (b) The mesio-lingual view of the fracture surface. The direction of crack propagation is shown by the white dashed arrow. (c) The occlusal view of the fracture origin, highlighted by the dashed circle.

Fig. 2. A large chipping in the left mandibular second molar (Tooth \#37, retainer) of a 3-unit zirconia-ceramic FDP. (a) An overview of the fractured left mandibular second molar. Fracture margins are highlighted by white solid arrows. (b) The disto-lingual view of the fracture surface. The direction of crack propagation is shown by black dashed arrows. (c) The higher magnification view of the region highlighted by the black square in Fig. 2b. (d) The occlusal view of the fracture origin, demarcated by solid black arrows in Fig. 2b.

Fig. 3. Delamination in the left mandibular first molar (tooth \#36, pontic) of a 4-unit zirconia-ceramic FDP. (a) An overview of the fractured left mandibular first molar. Fracture margins are highlighted by white solid arrows. (b) The disto-lingual view of the fracture surface. The direction of crack propagation is shown by black dashed arrows. (c) The magnified region highlighted by the large black square in Fig. 3b. (d) The higher magnification of milling trace lines in the area outlined by the small black square in Fig. 3b. 
Fig. 4. A small chipping in the left mandibular first molar (tooth \#36, pontic) of a 3-unit metal-ceramic FDP. (a) An overview of the fractured left mandibular first molar. Fracture margins are highlighted by white solid arrows. (b) The lingual view of the fracture surface. The direction of crack propagation is shown by the white dashed arrow. (c) The occlusal view of the fracture origin, highlighted by the dashed circle. 
Table 1 The incidence of fractures in zirconia-ceramic and metal-ceramic FDPs

\begin{tabular}{|c|c|c|}
\hline & $\begin{array}{c}\text { Zirconia-Ceramic } \\
\text { FDP }\end{array}$ & FDP \\
\hline Number of fractured FDPs & 12 & 6 \\
\hline Small chipping & 2 & 5 \\
\hline Large chipping & 9 & 0 \\
\hline Delamination & 1 & 1 \\
\hline
\end{tabular}


(a)

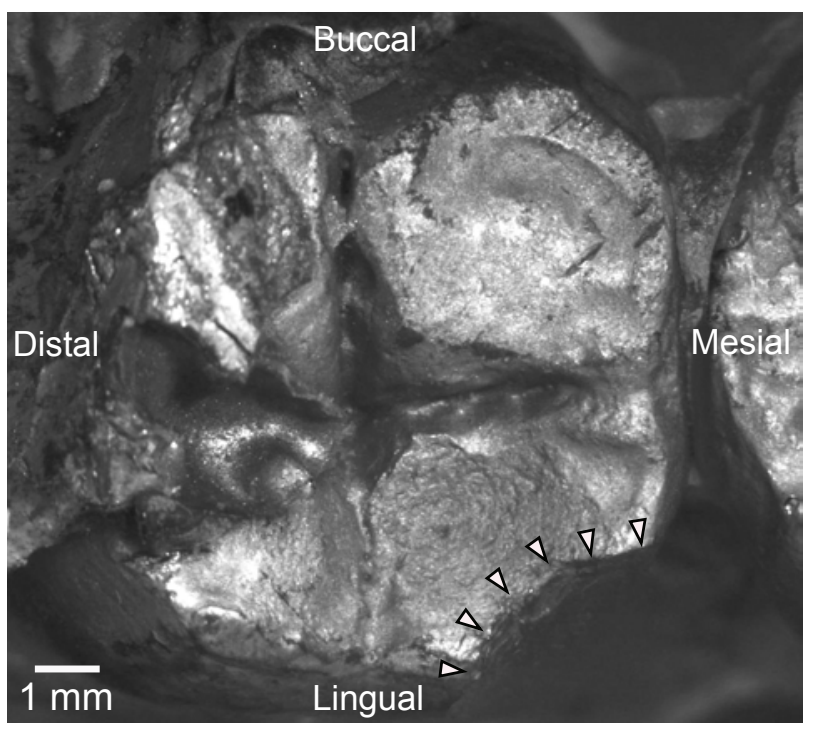

(b)

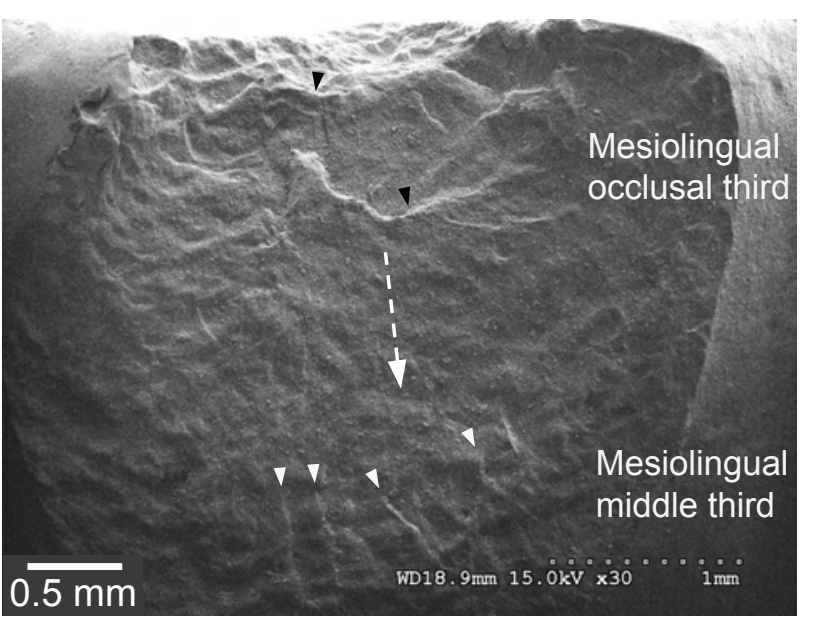

(c)

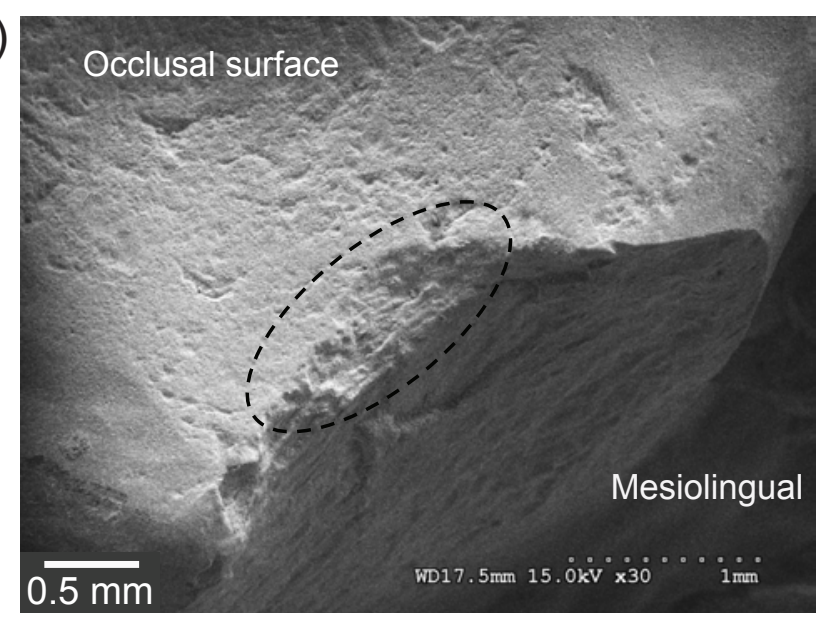


(a)

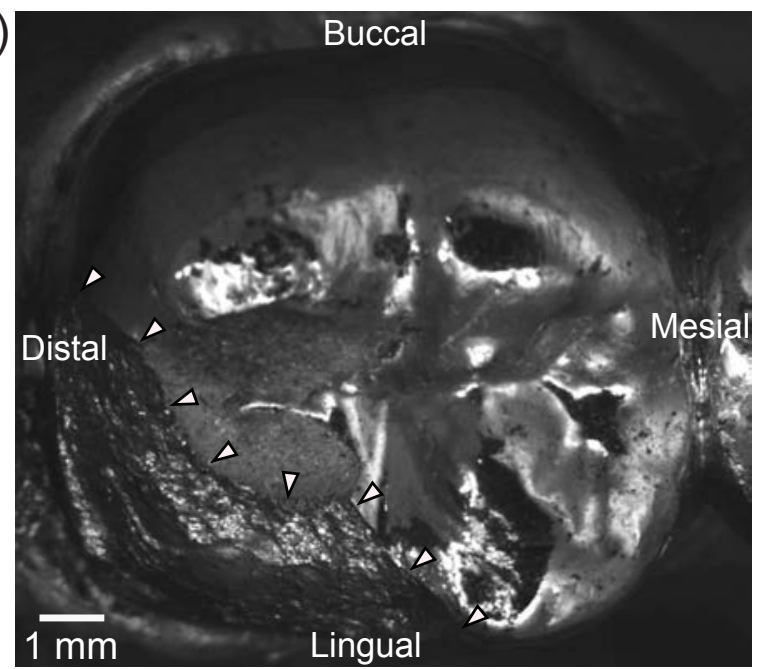

(c)

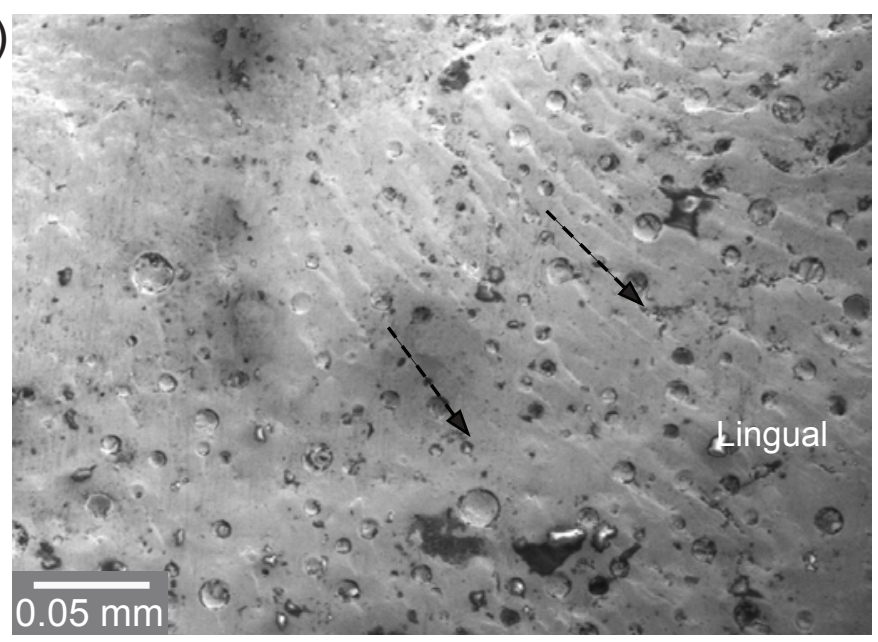$$
\text { 政 }
$$

(b)

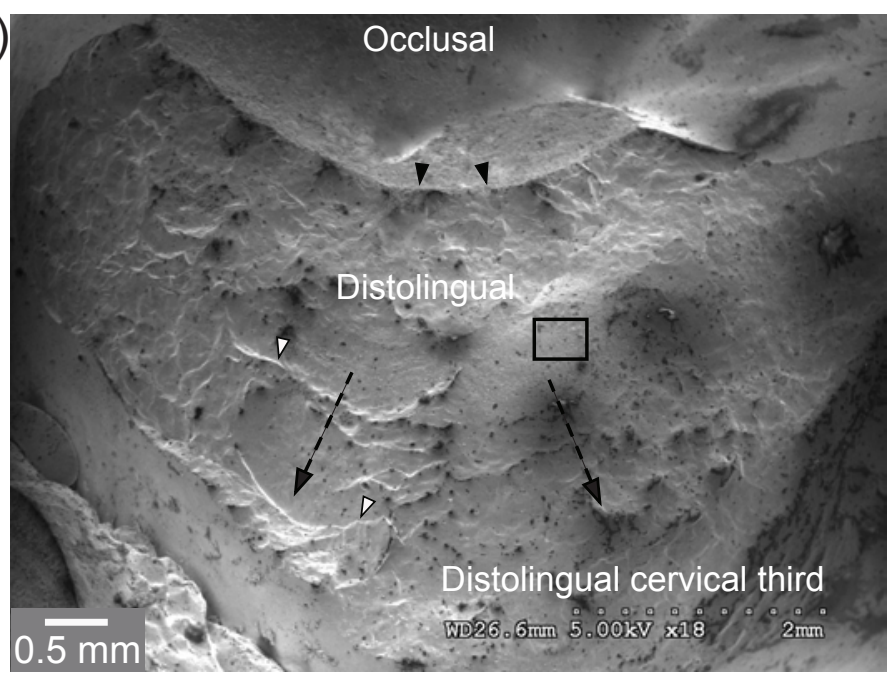

(d)

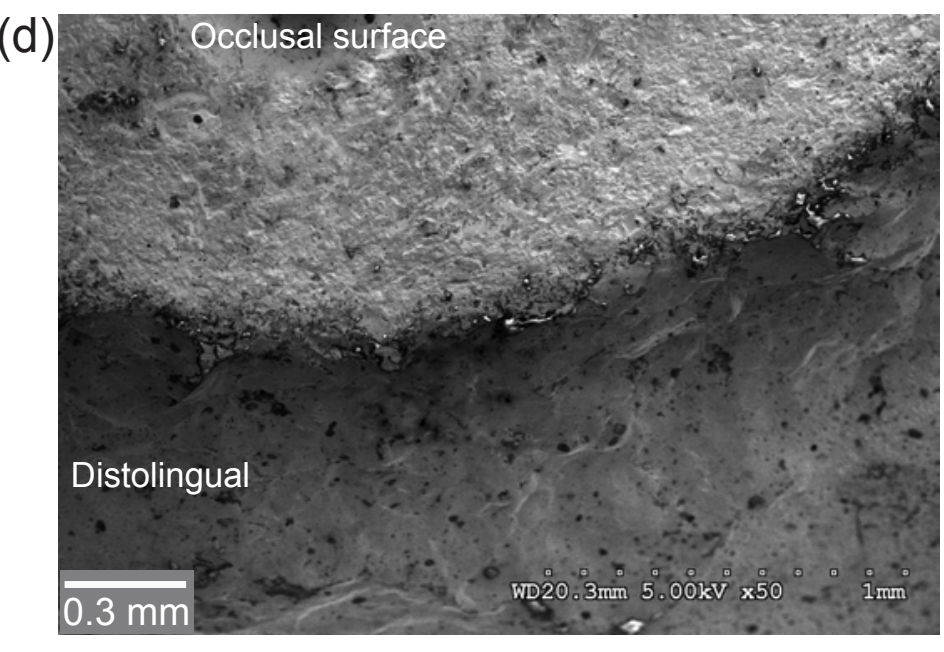

\section{Figure 2}


(a)

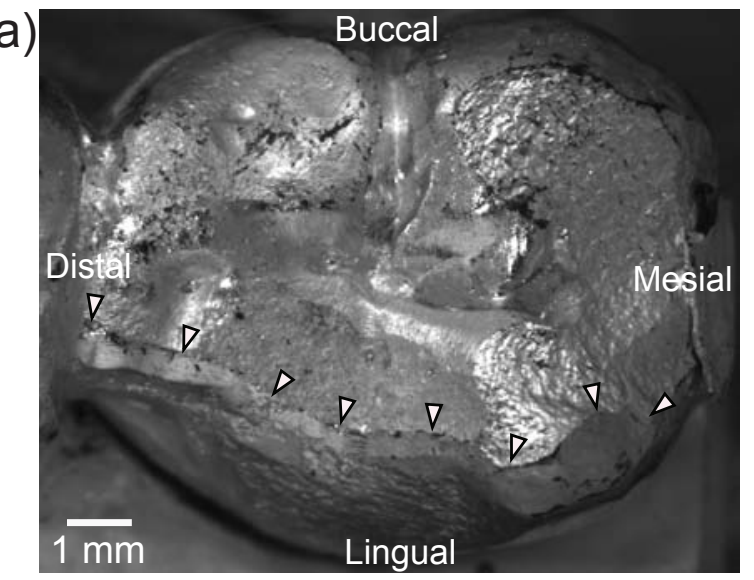

(c)

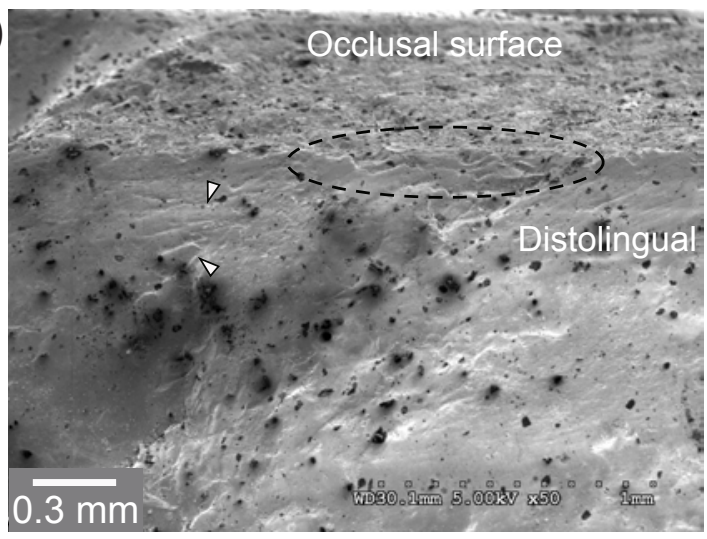

(c) $0.3 \mathrm{~mm}$ (b)

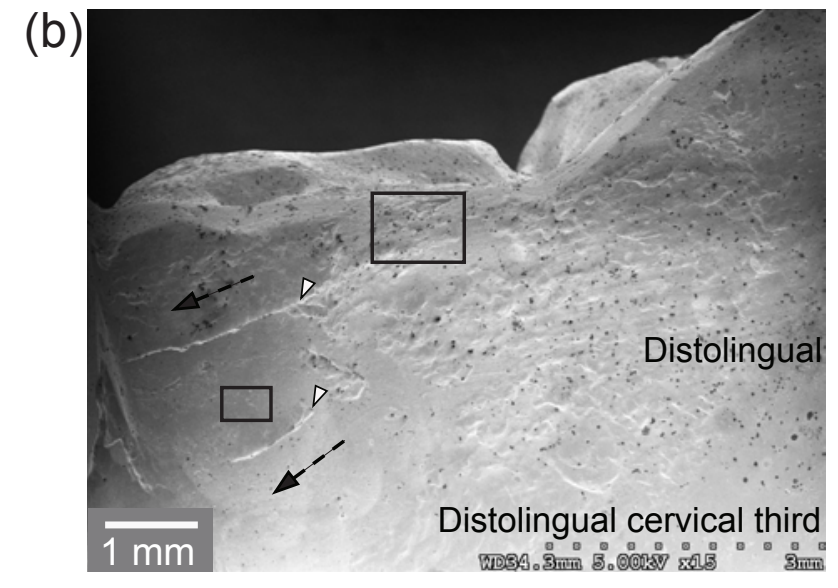

(d)

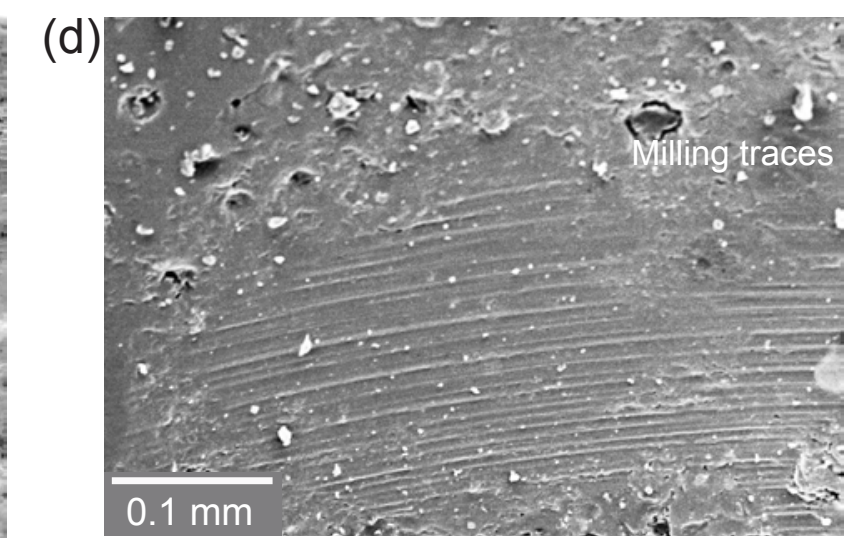




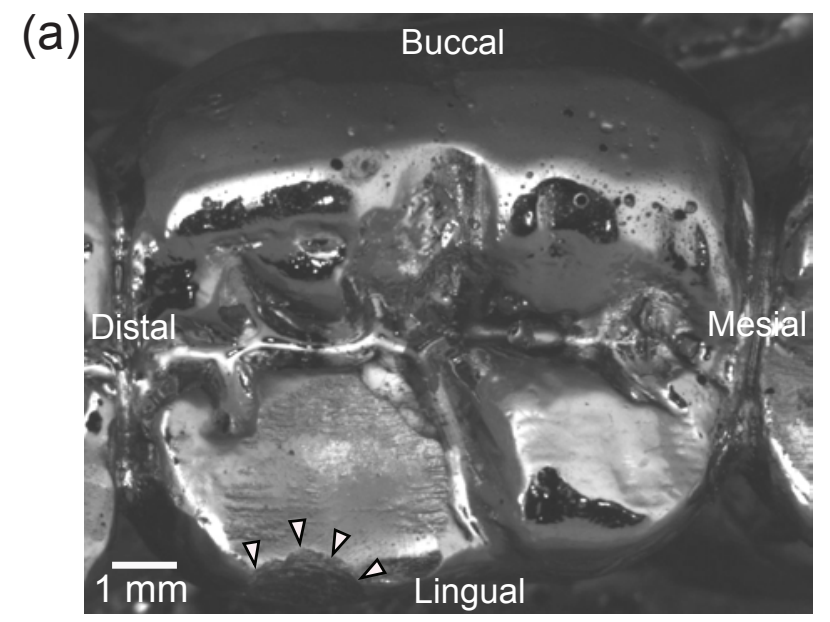

(b)

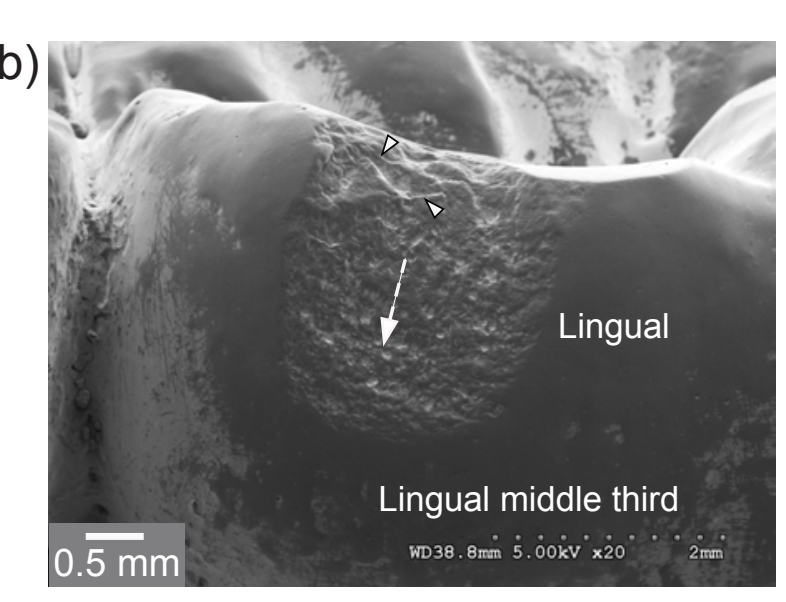

(c)

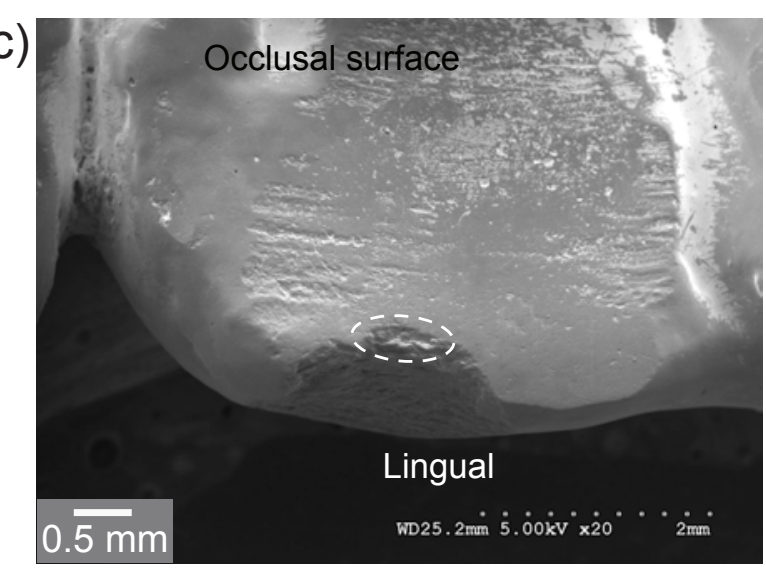

Figure 4

(a) Lingua .

.

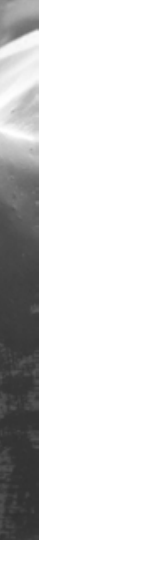
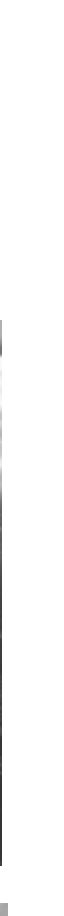

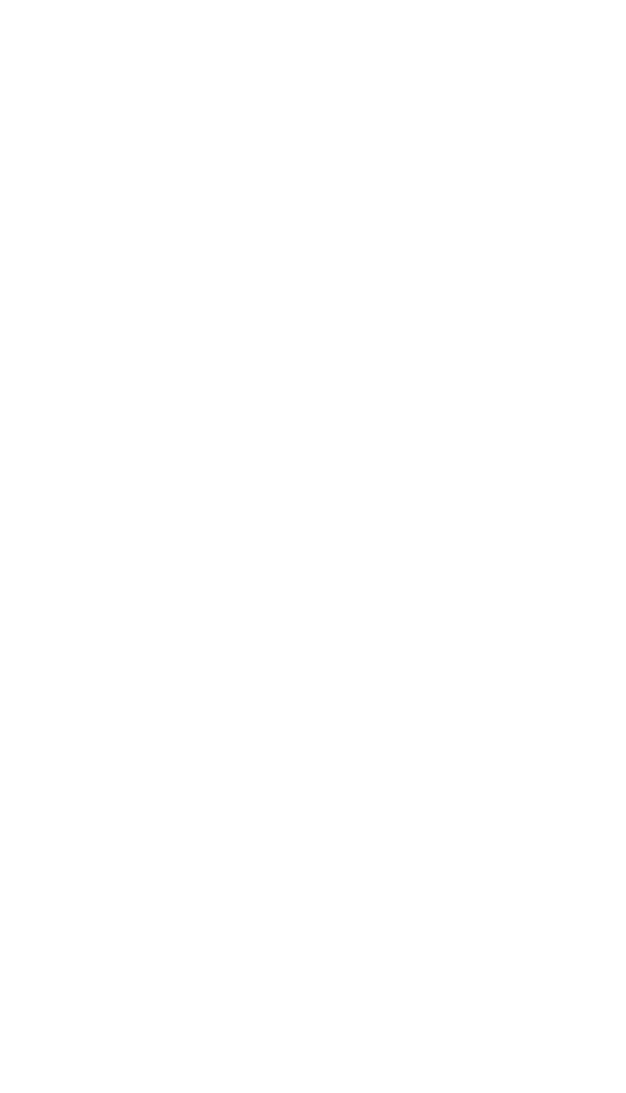

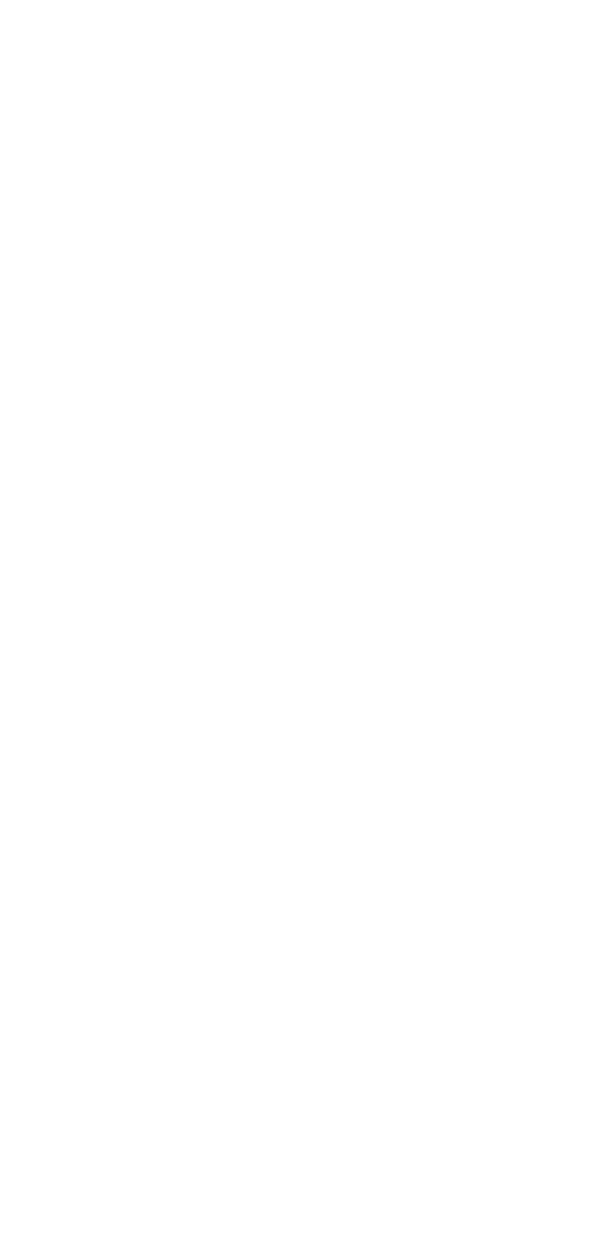

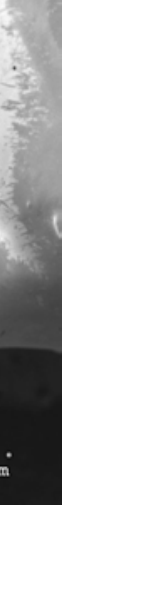

